\title{
A mobile X-POL weather radar for hydrometeorological applications in the metropolitan area of São Paulo, Brazil
}

\author{
A. J. Pereira Filho \\ Department of Atmospheric Sciences, Institute of Astronomy, Geophysics and Atmospheric Sciences, \\ University of São Paulo, São Paulo, Brazil
}

Correspondence to: A. J. Pereira Filho (apereira@model.iag.usp.br)

Received: 24 April 2012 - Published in Geosci. Instrum. Method. Data Syst. Discuss.: 23 May 2012

Revised: 7 September 2012 - Accepted: 17 October 2012 - Published: 13 November 2012

\begin{abstract}
This paper presents the first mobile X-band dualpolarization Doppler weather radar termed MXPOL operated by the Laboratory of Hydrometeorology (LABHIDRO) of the University of São Paulo, São Paulo, Brazil. It is used in graduate and under graduate courses, real-time monitoring and nowcasting of severe weather in the Metropolitan Area of São Paulo (MASP). It is one of the first of its kind to be used operationally to provide real-time high spatial resolution polarimetric data. MXPOL is an important component of a Hydrometeorological Forecast System (Pereira Filho et al., 2005) for MASP. This manuscript presents some instances of MXPOL polarimetric measurements of weather systems and their respective microphysical, dynamical and boundary layer features that can improve nowcasting.
\end{abstract}

\section{Introduction}

The metropolitan area of São Paulo (MASP) shown in Fig. 3a is within the Alto Tietê Basin where the population, agriculture, industry, commerce, transport and government activities are highly affected by severe weather associated with flash floods and mud slides as well as other damages caused by hail, lightning, and wind gusts during the warm season.

A trend in weather patterns in the past seven decades has been analysed. Hourly records indicate an increase of air temperature of $2.1{ }^{\circ} \mathrm{C}$, decrease in relative humidity of $7 \%$, increase in yearly precipitation of $400 \mathrm{~mm}$ and anomalies in wind speed and direction (Pereira Filho et al., 2007). In the past decade alone, an annual average of 20 severe weather episodes occurred in MASP, affecting hundreds of flood and mud sliding prone areas.
About $70 \%$ of such severe weather events are associated with local circulation induced by topographic and the MASP heat island (Ferreira et al., 2011) during the warm season. The most common local circulation is the sea breeze. The MASP is about $50 \mathrm{~km}$ distant from the Atlantic Ocean (Fig. 3a). Major flood episodes occur in mid afternoon hours while the sea breeze front pushes continent ward from SE against prevailing NW winds (approaching cold front), injecting a deeper layer of moisture over the MASP warmer and drier urban boundary layer. Deep thunderstorms develop in a matter of minutes to cause flash floods and other severe weather features. This manuscript will show an example of such flood related event.

An Integrated Hydrometeorological System for the State of São Paulo (SIHESP) was established to mitigate effects on population of recurrent extreme weather and climate conditions associated to environmental anthropic changes (Pereira Filho et al., 2007) in this very large urban environment. The SIHESP programme implemented a network of automatic weather stations, upgraded two weather radars, established high performance computing facilities for weather and regional climate prediction and developed the MXPOL weather radar. In particular, MXPOL was designed and built to monitor and to nowcasting weather systems over MASP and the Coast region of São Paulo state. Both regions are affected by floods, mud slides, heavy winds, lightning and hail that cause significant social and economical impacts (Pereira Filho et al., 2007).

Another important component of SIHESP is the use of high-resolution numerical weather prediction based on the Advanced Regional Prediction System-ARPS (Xue et al., 2003). The dynamics and physics of convective systems are 
explicitly resolved at higher spatial resolution with assimilation of MXPOL polarimetric variables. Timing, location, dimension, intensity and advection of convection cells are very difficult to forecast or even simulate (Weisman et al., 1997; Xue and Martin, 2006). But, fine resolution data assimilation (e.g. Hu et al., 2006a,b) can be done with MXPOL polarimetric measurements to include important mesoscale microphysical and dynamic features of weather system observed in MASP. This manuscript presents measurements of precipitating systems with MXPOL. Measurement campaigns with MXPOL were conducted in Eastern São Paulo state in 2007 and 2008.

The measurement campaigns were meant to verify the performance of MXPOL on clear air mode with few low elevation angles, longer pulse widths and horizontal polarization to measure boundary layer features late in the morning while sea breeze fronts are moving into MASP. Radar measurements of precipitation were performed with eleven or more elevation angles, shorter pulse widths and simultaneous horizontal and vertical polarization.

Reflectivities above $20 \mathrm{dBZ}$ were deemed associated with significant rainfall rates in this manuscript. Measurements were made and raw data archived, processed and displayed with the interactive radar information system (IRIS) developed by SIGMET. The radar antenna was placed pointing vertically during the passage of a cold front with slow azimuth rotation, short pulse width, high signal sampling rate, in horizontal and vertical polarization mode. Lightning temporal and spatial distribution from an integrated detection network was compared with concomitant MXPOL polarimetric variables. Measurements of a conventional S-band weather radar (SPWR) were also compared to respective MXPOL ones for checking spatial coherence and rainfall rate spatial distribution. It is well known that X-band radars suffer from attenuation caused not only by intervening rainfall (Berne and Uijlenhoet, 2006) but also by cloud, i.e. the nonprecipitating component of condensed atmospheric water (Pujol et al., 2007). Attenuation affects variables determined by radar power measurements such as reflectivity $\left(Z_{\mathrm{HH}}\right.$, $\left.Z_{\mathrm{VV}}\right)$ and differential reflectivity $\left(Z_{\mathrm{DR}} \sim Z_{\mathrm{HH}} / Z_{\mathrm{VV}}\right)$. These can be corrected by specific techniques (e.g. Vivekanandan et al., 2003). Under heavy rainfall conditions, the transmitted power along the radar beam going through the storm and its corresponding return scattered signal by hydrometeors in the volume illuminated by the radar beam will be attenuated. Larger raindrops have an elliptical cross section and more energy is backscattered along the horizontal axis than in the vertical. Thus, reflectivities will be less than the true value. In this instance, $Z_{\mathrm{HH}}$ will be more severely attenuated and $Z_{\mathrm{DR}}$ might become smaller or even negative since it is the logarithmic ratio of $Z_{\mathrm{HH}}$ and $Z_{\mathrm{VV}}$. The above variables are used to estimate rainfall rates and rainfall accumulation. It also might cause a distortion of the storms morphology at longer ranges (Fig. 9f).
Since the advent of dual polarization X-band weather radars, attenuation may be corrected accordingly (Anagnostou et al., 2006; Gorgucci and Chadrasekar, 2005; Park et al., 2005) and rainfall rates estimated (Matrosov et al., 2002; Anagnostou et al., 2004).

On the other hand, few studies were proposed to estimate cloud attenuation and, consequently, to correct Xband radar observations (Georgis et al., 2006). The focus of this manuscript is on the original MXPOL measurements of weather systems without any attenuation corrections. Section 2 describes the main features of MXPOL and its modus operandi. Section 3 describes antenna pattern measurements, ground clutter features over MASP and vertical pointing measurements of light rainfall. Measurements of sea breeze circulation and gust fronts are shown in conjunction with thunderstorm initiation in Sect. 4. Qualitative interpretation of polarization measurements at the leading edge of a vigorous thunderstorm, and microphysical characteristics of a heavy precipitation events are described in the Sect. 5. A summary of the results are presented in Sect. 6.

\section{Radar system description}

MXPOL is a dual polarization X-band radar system that can be switched to single polarization mode. In horizontalonly transmitted mode with longer pulse length, sensitivity of the radar is better than $3 \mathrm{~dB}$ when compared to a dualpolarization mode of operation. In the horizontal-only transmitted mode, the dual-channel receiver is capable of measuring both co- and cross-polarised backscattered signals.

A slant $45^{\circ}$ transmitted mode with short pulse length is used for measuring precipitation. Figure 1 shows the block diagram of MXPOL. The antenna control and signal processing are the SIGMET RCP8 (radar/antenna control processor) and RVP8 (Digital IF Receiver and Signal Processor) units, respectively. IRIS is a LINUX based software that controls both RVP8 and RCP8 processes. It also displays real-time PPI and RHI scans and generates volume scans.

The measured variables are the clutter corrected reflectivity $(Z)$ and raw reflectivity without clutter filtering $\left(Z_{\mathrm{T}}\right)$, radial velocity $\left(V_{\mathrm{r}}\right)$, spectral width $(\mathrm{SW})$, differential reflectivity $\left(Z_{\mathrm{DR}}\right)$, differential propagation phase $\left(\varphi_{\mathrm{DP}}\right)$, specific differential phase $\left(K_{\mathrm{DP}}\right)$, magnitude $\left(\rho_{\mathrm{oHV}}\right)$ and phase $\left(\varphi_{\mathrm{HV}}\right)$ of correlation coefficient of co-polarization horizontal and vertical backscattered signals. In the case of horizontal-only transmit mode only co-polarization channel-based $Z, Z_{\mathrm{T}}, V_{\mathrm{r}}$, and $W$ are archived by the radar processor.

An additional feature is that the dual-channel receivers can be programmed to record both co- and cross-polarization received signals for estimating linear depolarization ratio and cross correlation coefficient between co- and cross-polarised backscattered signals. The analysis software generates radar products from raw archived polarimetric measurements. It 




Fig. 1. Block diagram of the MXPOL weather radar.

displays measurements in constant elevation and altitude projections and vertical cross sections.

These radar-based products include cloud tops that are determined by reflectivity greater than a given threshold (e.g. $10 \mathrm{dBZ}$ ); rainfall accumulation obtained from hourly integration of the rainfall rate field at a low elevation angle or at a constant altitude obtained every five minutes; vertically integrated liquid water or VIL that is an integration of estimated water content from $Z$ in the vertical column at a given horizontal resolution (e.g. $1 \mathrm{~km} \times 1 \mathrm{~km}$ ); estimated wind speed and direction from radial velocities; maximum value profiles; cross-sections or range height indicator RHI that is centred at the radar; specified horizontal and vertical cross-sections arbitrarily selected; storm motion forecast, storm tracking and forecasting, warning and centroid plotting. These products are derived from the centre of mass of individual storms to track its displacement in space and time and to forecast its future position by simple extrapolation.
The storm motion forecast is the position of the storm as a whole without any changes in shapes and integration of rainfall rates. So, tracking is a diagnostic toll and forecasting a prognostic toll to help the forecaster especially under isolated convection conditions under weak synoptic forcing, characterised by a more random type of displacement of storms. These products were developed by SIGMET that provide manuals online (www.sigmet.com).

Table 1 shows MXPOL's antenna parameters: reflector, pedestal, transmitter and receiver. Each parameter was tested as part of the acceptance procedure and performance was found to be satisfactory or better than the specification of the manufacturer.

MXPOL includes a six cylinder 180 HP WV Diesel truck, 18 KVA Diesel generator that can sustain one week long operation if necessary, pneumatic suspension, automatic levelling with auxiliary supports for steep terrain, GPS, and wideband Internet communication systems, SIGMET antenna 



Fig. 2. Antenna diagram of the MXPOL transmission and reception of azimuthal scanning of horizontal (a) and vertical (b) polarizations.

Table 1. Main parameters of the MXPOL.

\begin{tabular}{l}
\hline MXPOL system \\
\hline REFLECTOR \\
\hline Parabolic \\
Diameter $2.44 \mathrm{~m}$ \\
Antenna Gain $44 \mathrm{~dB}$ \\
HPBW at $3 \mathrm{~dB}<1.0^{\circ}$ \\
\hline Pedestal \\
\hline Azimuth scan 0 to $360^{\circ}$ \\
Elevation scan 0 to $90^{\circ}$ \\
Maximum scan $36^{\circ} \mathrm{s}-1 \mathrm{Pointing}$ imprecision $<0.1^{\circ}$ \\
\hline Transmitter \\
\hline Magnetron \\
Frequency $9.4 \mathrm{Ghz}$ \\
Peak power $80 \mathrm{KW}$ \\
Pulse modulation \\
PRF 500 to $5000 \mathrm{~Hz}$ \\
Pulse width 0.2 to $2 \mu \mathrm{s}$ \\
Linear polarization $(\mathrm{H}, \mathrm{V})$ simultaneous \\
Solid state modulator \\
Duty cycle 0.001 \\
\hline Reception \\
\hline Two digital channels $(\mathrm{H}, \mathrm{V})$ \\
Radar Noise Figure $<2.5 \mathrm{~dB}$ \\
Dynamic range $(\mathrm{H}, \mathrm{V})>80 \mathrm{~dB}$ \\
ADC 14 bits \\
Local oscillator $\mathrm{DAFC}$ \\
MDS (H, V) $-113 \mathrm{dBm}$ at $2 \mu \mathrm{s}$ \\
\hline
\end{tabular}

positioning system, microwave power signal generator and meter, and SIGMET automatic calibration software.

The radar system was design and developed in Brazil. Major radar parts such as magnetron, wave guides, duplexers, switches and receivers are from USA; antenna and pedestal parts from Finland and motors and controls from Italy; truck and cabin were developed in Brazil.

\section{MXPOL data quality}

In general, radar measurements are determined by radar receiver characteristics and can be affected by ground clutter. The extent of ground clutter impact on a precipitation measurement depends on antenna side lobes. Also, co-pol antenna beam widths in horizontal and vertical polarization should be matched so differential reflectivity and propagation phase measurements are not biased by strong spatial gradients in precipitation.

The antenna feed and reflector were tested to check the antenna gain and beam width. A test signal microwave power generator at $9.4 \mathrm{GHz}$ at $14 \mathrm{dBm}$ was connected to the feed-horn antenna pointing towards the radar reflector a minimum far-field distance. The received signal by the MXPOL antenna was measured by the RVP8 digitizer. The antenna scan was controlled by RCP8 processor and its position recorded. The test feed-horn was aligned to the radar antenna and performed a scan in azimuth and elevation for both $\mathrm{H}$ and $\mathrm{V}$ polarizations.

The antenna beam patterns for both horizontal and vertical polarizations are shown in Fig. $2 \mathrm{a}$ and $\mathrm{b}$, respectively. The horizontal polarization azimuth scan yielded $\mathrm{HPBW}=0.95^{\circ}$ at $-3 \mathrm{~dB}$ and first sidelobe at $-26 \mathrm{~dB}$ and, the elevation scan, $\mathrm{HPBW}=0.97^{\circ}$ at $-3 \mathrm{~dB}$ and the first sidelobe at $-28 \mathrm{~dB}$. These results were within specifications. 

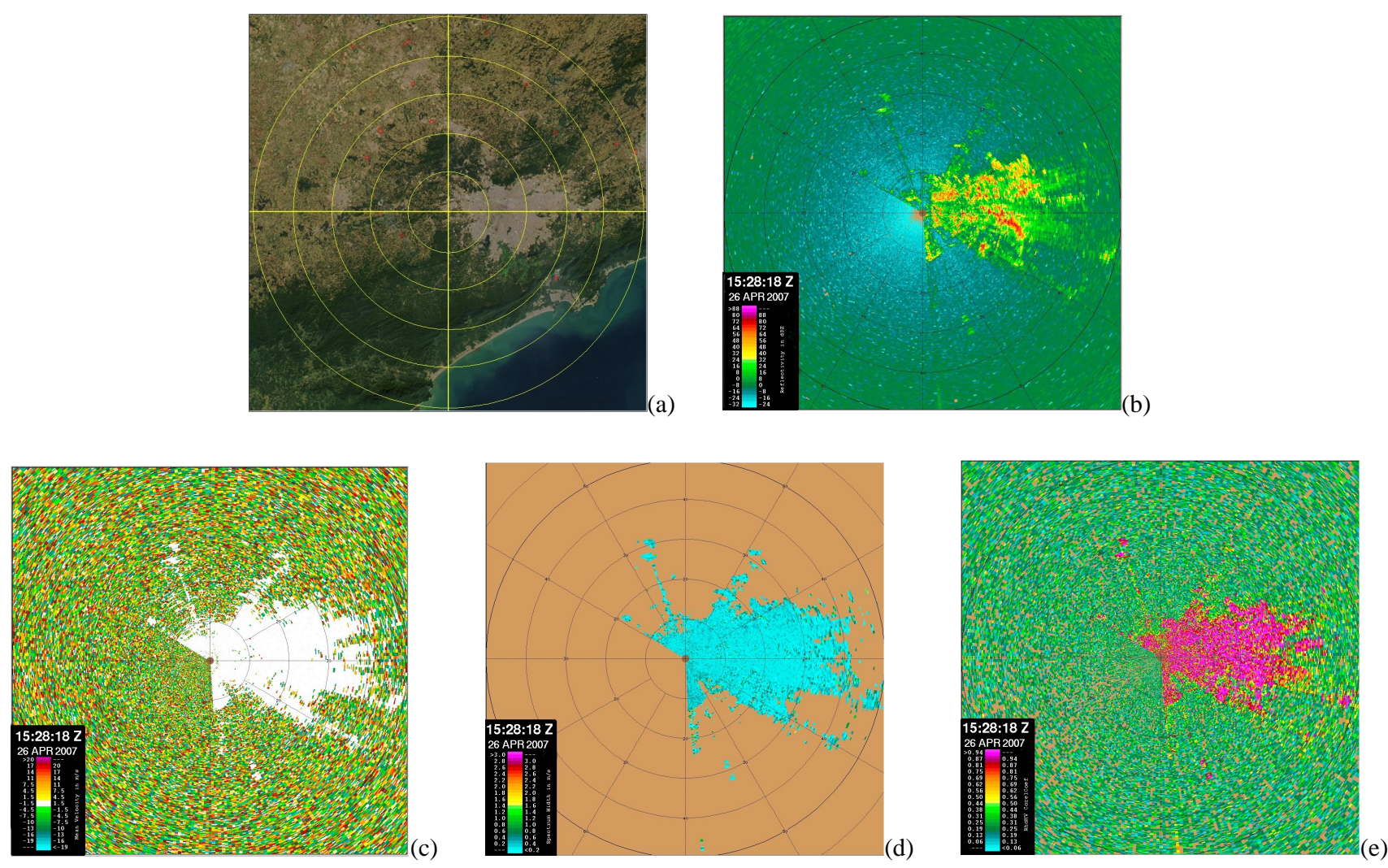

Fig. 3. (a) ACQUA/MODIS image of eastern São Paulo state on 20 July 2003 . The cross indicates the MXPOL site $\left(23^{\circ} 32.2^{\prime} \mathrm{S} ; 46^{\circ} 52.8^{\prime} \mathrm{W}\right)$ in Barueri City, São Paulo, Brazil, on 26 April 2007. The large brown area east of the MXPOL site is the MASP. Concentric circumferences spaced every $20 \mathrm{~km}$. Image source: http://visibleearth.nasa.gov/. PPI at $0.6^{\circ}$ elevation of reflectivity $-Z_{\mathrm{h}}(\mathbf{b}) \mathrm{dBZ}$, radial velocity $-V_{\mathrm{r}}(\mathbf{c})$ $\mathrm{m} \mathrm{s}^{-1}$, spectral width $-\mathrm{SW}$ (d) $\mathrm{m} \mathrm{s}^{-1}$, and correlation coefficient VH $-\rho_{\mathrm{OHV}}$ (e) obtained with MXPOL at 15:28 UTC on 26 April 2007. Ranges, directions and colour scales are indicated in each PPI.

MXPOL measurements were made in the west site of MASP (Fig. 3a) during the passage of an eastward moving squall line associated with a cold front on 26 April 2007 (Pereira Filho et al., 2007). Initially, clear air scan mode was performed for three low antenna elevation angles $(0.6$, 1.2 and $2.0^{\circ}$ ) with maximum sensitivity to measure boundary layer and ground returns features. In the rainfall mode, MXPOL scans the atmosphere using eleven elevation angles between 0.6 and $24.0^{\circ}$.

Figure $3 \mathrm{~b}$ to $\mathrm{d}$ shows $0.6^{\circ}$ PPIs of reflectivity $\left(Z_{\mathrm{h}}\right)$, radial velocity $\left(V_{\mathrm{r}}\right)$, and spectral width $(W)$. Surface winds were from NNW at $3 \mathrm{~m} \mathrm{~s}^{-1}$ and gusting up to $7 \mathrm{~m} \mathrm{~s}^{-1}$ right before the passage of the squall line over São Paulo City. As an aside, surface winds are retrieved by assuming direction and speed constants within a horizontal sector of azimuths and ranges. The $0.6^{\circ}$ elevation PPI of the reflectivity field is completely contaminated by ground echoes within the MASP. Reflectivity above $60 \mathrm{dBZ}$ are associated to ground echoes from hills, mountains, buildings, towers and other urban structures.
A time animation of such PPIs (not shown) indicated weaker echoes related to fair weather clouds. In early afternoon, no mid to deep clouds were observed. The area of ground echoes (Fig. 3b) is similar in shape to the satellite image (Fig. 3a). The low noisy reflectivity area between $180^{\circ}$ and $300^{\circ}$ azimuths is the black sector of the cabin of the radar. Figure $3 \mathrm{c}$ shows the radial velocity field where zero radial velocities are co-located with MASP. Furthermore, the spectral width (Fig. 3d) were between $0.2 \mathrm{~m} \mathrm{~s}^{-1}$ and $1.4 \mathrm{~m} \mathrm{~s}^{-1}$ at the centre and borders of MASP region, respectively. Surface winds were strong and gusting yielded turbulence and mixing of this urban boundary layer rich in particles.

Backscatter characteristics of the horizontally and vertically polarised echoes are similar within the MASP, so $\rho_{\mathrm{oHV}}$ was higher (Fig. 3e). Thus, low elevation polarimetric measurements yielded valuable inside to distinguishing weather from ground echoes under clear air conditions over MASP. In general, ground echoes are filtered out based on radial velocity and reflectivity features at the lower elevations angles. No filtering was applied to Fig. 3 so to show ground echoes in 



Fig. 4. CAPPI of rainfall rates at $3-\mathrm{km}$ altitude (left panel) and echo tops (right panel) with $1 \times 1-\mathrm{km}$ horizontal resolution estimated with the São Paulo Weather Radar (SPWR) at 16:16 UTC (a) and the 12:00 UTC sounding at station 83779 in São Paulo City (b) on 22 May 2007. It is indicated the site $\left(23^{\circ} 33.4^{\prime} \mathrm{S} ; 46^{\circ} 44.1^{\prime} \mathrm{W}\right)$ of the MXPOL during the event.

MASP. Under clear air conditions such as the one depicted in Fig. 3, the correlation coefficient is high and radial velocities are zero within the MASP. Elsewhere, the correlation coefficient is low and radial velocity is noisy. Animation loops (not shown) of that day showed moving clouds on top of that fairly constant ground clutter conditions; so one can distinguish between weak weather echoes and ground echoes just by inspecting the animation. But, to estimate rainfall rates, one has to filter out ground echoes and part of the information is lost in the process. In clear air conditions, it is best to leave the data unfiltered and use it only if precipitating clouds start to develop.

Vertically pointing measurements were made with MXPOL during a cold front passage on 22 May 2007. Figure 4 shows a 3-km CAPPI of rainfall rates and respective echo tops $(Z>18 \mathrm{dBZ})$ estimated with SPWR at 16:16 UTC and the 12:00 UTC sounding at Campo the Marte, São Paulo, a few kilometers east of MXPOL site. The precipitating system was moving northeastward. Rainfall rates less than $40 \mathrm{~mm} \mathrm{~h}^{-1}$ were observed eastward and lower than $2 \mathrm{~mm} \mathrm{~h}^{-1}$ westward with $18 \mathrm{dBZ}$ echo tops between 6 and $3.5 \mathrm{~km}$ in these two regions, respectively. There is $45 \mathrm{~min}$ difference between MXPOL (15:30 UTC) and SPWR (16:16 UTC) measurements. If one takes into account the 45-min NE displacement of the cold front, there is good agreement between both echo tops.

MXPOL measurements were made at the rear flank of the cold front. The location of MXPOL is indicated in Fig. 4a. The 12:00 UTC sounding indicated a deep moisture layer extending from the surface to about $300 \mathrm{hPa}$. The wind profile indicates a 145 knot westerly jet around $150 \mathrm{hPa}$ with very small directional shear. Northwest winds at the surface 

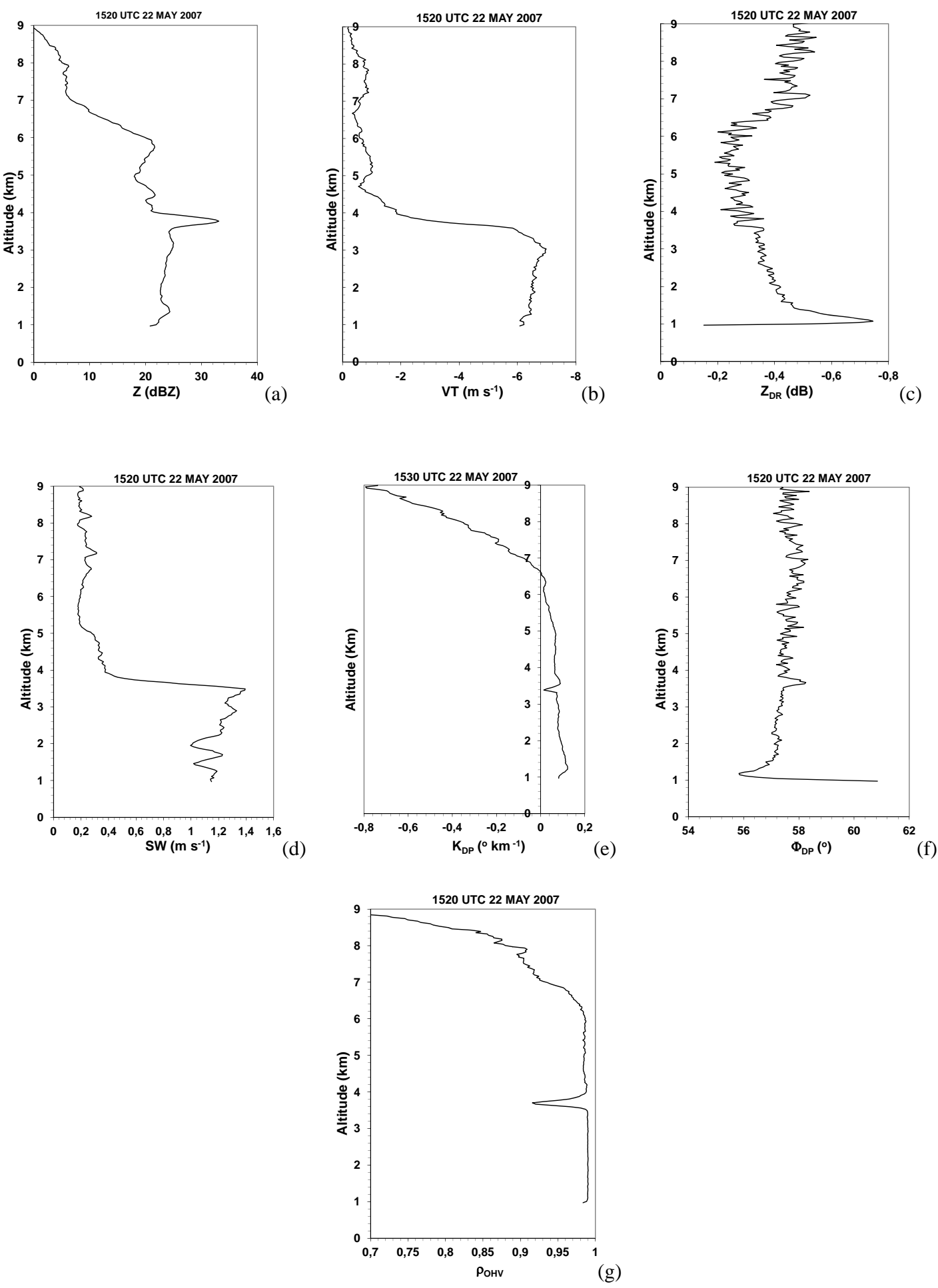

Fig. 5. Vertical profiles of reflectivity $-Z_{\mathrm{h}}$ (a) $\mathrm{dBZ}$, radial velocity $-V_{\mathrm{T}}$ (b) $\mathrm{ms}^{-1}$, differential reflectivity $-Z_{\mathrm{DR}}(\mathbf{c})$ spectral width SW (d), specific differential phase $-K_{\mathrm{DP}}(\mathbf{e})$ degree $\mathrm{km}^{-1}$, differential propagation phase $-\varphi_{\mathrm{DP}}$ (f) degree, and correlation coefficient $\mathrm{VH}-\rho_{\mathrm{oHV}}(\mathbf{g})$ obtained with MXPOL at 15:30 UTC on 22 May 2007. Full clockwise antenna scan $\left(6.0^{\circ} \mathrm{s}^{-1}\right)$ at $90^{\circ}$ elevation for pulse width $=0.2 \mathrm{~s}, \mathrm{PRF}=1000 \mathrm{~Hz}$ and 256 samples, $\Delta z=35$. 
veering with height indicate warm advection on the warm sector of the cold front. The zero degree celsius isotherm was at $3792 \mathrm{~m}$ altitude.

Figure 5 shows vertical profiles from ground level of $Z_{\mathrm{h}}, V_{\mathrm{r}}, Z_{\mathrm{DR}}, W, \varphi_{\mathrm{DP}}, K_{\mathrm{DP}}$, and $\rho_{\mathrm{oHV}}$ at $15: 20 \mathrm{UTC}$ on 22 May 2007. Figure 5a shows the profile of $Z_{\mathrm{h}}$. The altitude of MXPOL was $760 \mathrm{~m}$ so heights are changed to altitude by adding $760 \mathrm{~m}$. Clouds tops of $5 \mathrm{dBZ}$ were at $7860 \mathrm{~m}$ altitude. The melting layer was $280 \mathrm{~m}$ deep between $3940 \mathrm{~m}$ and the altitude of MXPOL was $760 \mathrm{~m}$ so heights are changed to altitude by adding $760 \mathrm{~m}$. Clouds tops of $5 \mathrm{dBZ}$ were at $7860 \mathrm{~m}$ altitude. Noteworthy, MXPOL has a much lower MDS (less than $-20 \mathrm{dBZ}$ ) than the SPWR (greater than $15 \mathrm{dBZ}$ ). Thus, cloud tops are better determined with MXPOL. Furthermore, its beam width is narrower. SPWR was used mainly to show the horizontal structure of the back part of the cold front since MXPOL was scanning pointing vertically.

The melting layer was $280 \mathrm{~m}$ deep between 3940 and $3660 \mathrm{~m}$. It is in agreement with the higher altitude of the zero degree celsius given the warming of the lower troposphere by latent heating release. Ice crystals right above the melting layer have $Z_{\mathrm{h}} \sim 20 \mathrm{dBZ}$, while small drops below the melting layer have $Z_{\mathrm{h}} \sim 25 \mathrm{dBZ}$. In the melting layer $Z_{\mathrm{h}}$ reaches a $34 \mathrm{dBZ}$ maximum value. Raindrops were small and spherically shaped (local observations). In this case, attenuation is less significant and $Z_{\mathrm{DR}}$ should be zero (Zrnic et al., 2006). Above the melting layer, cold microphysics is dominant; reflectivity of snow and ice particles are in general 5 times less than raindrops equivalent (e.g. below the melting layer) due to the complex refractivity index (radar equation). These were the very first measurements of the kind in South America, even though is a common placed in many developed countries. It reveals cold and warm microphysics behind a typical cold front.

The vertical velocity profile in Fig. $5 b$ indicates speeds between $-1.2<V_{\mathrm{r}}<-0.5 \mathrm{~m} \mathrm{~s}^{-1}$ above the melting layer and $-7.0<V_{\mathrm{r}}<-6.0 \mathrm{~m} \mathrm{~s}^{-1}$ below. The terminal velocity tends to decrease as the small drops reach the surface. In general, Doppler measurement is the sum of the reflectivity-weighted terminal fall speed and the vertical air velocity, but in the case of a decaying cold front with very light rainfall rates, to a good first approximation, radial velocities were used to indicate the bulk of terminal velocities. At the melting layer, the terminal velocity increased exponentially from -1.9 to $-5.8 \mathrm{~m} \mathrm{~s}^{-1}$. The spectral width profiles in Fig. 5c shows that turbulence is below $0.4 \mathrm{~m} \mathrm{~s}^{-1}$ above the melting layer and between $1.0 \mathrm{~m} \mathrm{~s}^{-1}$ and $1.4 \mathrm{~m} \mathrm{~s}^{-1}$ below it. The profiles of $Z$ varies between -0.2 to $-0.5 \mathrm{~dB}$. Higher variation of $Z_{\mathrm{DR}}$ below $1000 \mathrm{~m}$ height is a near-field effect (electromagnetic field dependence on the antenna shape and distance at close ranges), but above it between 1.5 to $2.5 \mathrm{~km}$ it averages $-0.36 \mathrm{~dB}$, a bias since the layer was populated by small drops yielding light rainfall (local observations). The $Z_{\mathrm{DR}}$ bias is related to the radar hardware rather than attenuation. It is recommended that vertically pointing measurements are performed regularly to check for hardware related biases on $Z_{\mathrm{DR}}$. Under light rain conditions it should be zero. If not, the bias is removed from $Z_{\mathrm{DR}}$. It can be done afterwards without affecting other polarimetric measurements that are independent of power.

The differential propagation phase shown in Fig. 5e is fairly constant below the melting layer $\left(\sim 57^{\circ}\right)$ down to $1 \mathrm{~km}$ height. It increases at the melting layer and fluctuates around $58^{\circ}$ above it. The $1^{\circ}$ increase in the differential propagation phase within the melting layer is consistent with Melnikov et al. (2005). The specific differential phase shown in Fig. $5 \mathrm{f}$ is slightly positive from the surface to $6 \mathrm{~km}$ height and become negative above it. It indicates less fluctuation below the melting layer and more above it. Finally, the correlation coefficient HV in Fig. 5g shows fairly constant high values $(>0.98)$ below and above the melting layer and significant lower values at the melting layer and close to the cloud top. It also indicates the good quality of MXPOL polarimetric measurements. Good data quality is related to radar hardware except for the $Z_{\mathrm{DR}}$ bias. The correlation coefficient for precipitating targets should be as close to one as possible. One might note that most of the attenuation is caused by heavy precipitation. Unfortunately, the SPWR is an old conventional broad beam width that does not allow the type of comparison with MXPOL. The later has been used to evaluate the old one. And indeed SPWR has several limitations. One is related to the bright-band effects that tend to overestimate rainfall rates under stratiform precipitation conditions.

\section{Boundaries and thunderstorm initiation}

Figure $6 \mathrm{a}$ and $\mathrm{b}$ shows $2^{\circ}$ PPIs of the reflectivity field at 19:46 and 20:25 UTC on 16 January 2008, respectively. The reflectivity fields were obtained at $5 \mathrm{~min}$ time interval and animated displays of them were used to visualise moving boundaries that show as fine lines of low reflectivities. Colliding lines tend to trigger convection as well those moving through the topographic features. Figure 6a shows intense convective cells located towards NE of the MXPOL and along the $120^{\circ}$ azimuth. Ground echoes (hills, buildings, power lines, etc.) were observed within 30-km range.

A very fine line of reflectivity between -5 and $10 \mathrm{dBZ}$ at the $30-\mathrm{km}$ range almost perpendicular to $150^{\circ}$ azimuth was moving towards MXPOL and associated with the local late afternoon sea breeze front at 19:48 UTC (16:48 LT). The convective cells towards the north produced a gust front moving southwestward with reflectivities between $-10 \mathrm{dBZ}$ and $-5 \mathrm{dBZ}$ virtually parallel to the $120^{\circ}$ azimuth. It intercepted the sea breeze front near the $30-\mathrm{km}$ range and $120^{\circ}$ azimuth where just to the west an area of echoes between 10 and $25 \mathrm{dBZ}$ was observed at 19:48 UTC (Fig. 6a).

These two colliding boundaries moved along the sea breeze front. A deep and intense convective cell was observed at 20:25 UTC exactly where the boundaries collided. 

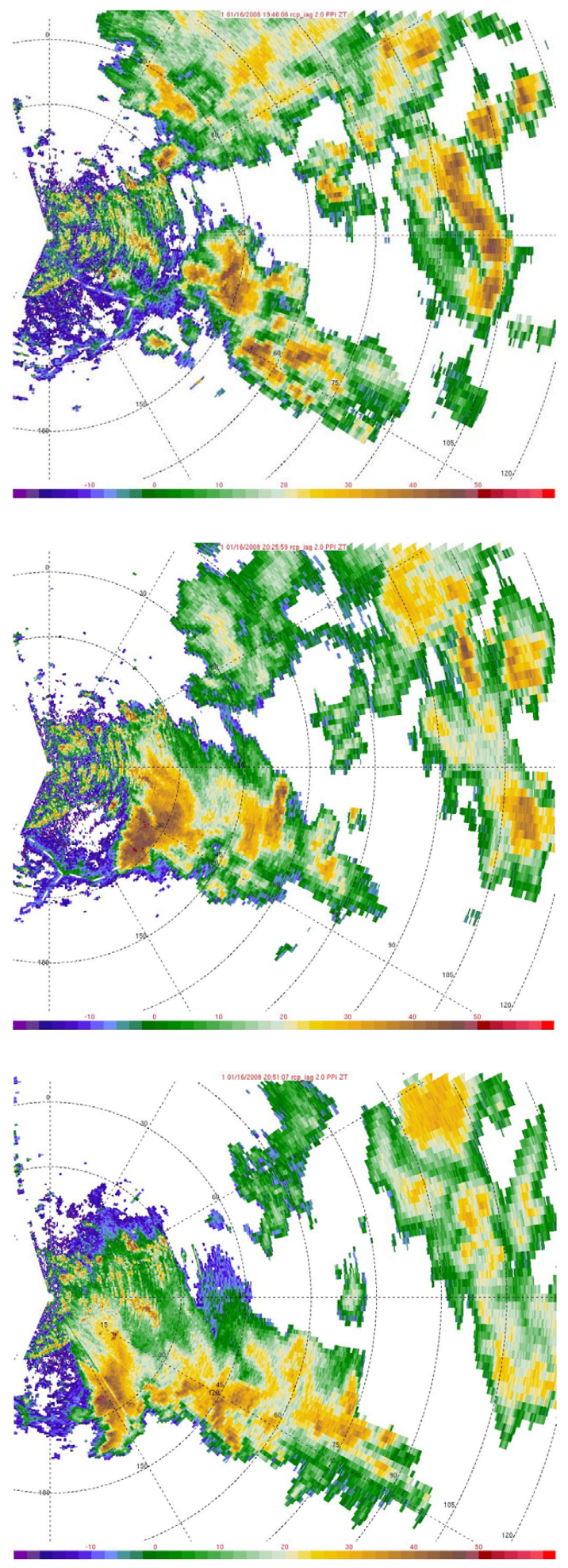

Fig. 6. $2^{\circ}$ PPI of reflectivity $\left(Z_{\mathrm{h}}-\mathrm{dBZ}\right)$ at 19:46UTC (a), 20:25 UTC (b) and 20:51 UTC (c) obtained with MXPOL on 16 January 2008. Colour scale is indicated. Dashed white line shows the position of the moving boundaries.


Fig. 7. $2^{\circ}$ PPI of reflectivity $-Z_{\mathrm{h}}$ (a) and differential reflectivity - $Z_{\mathrm{DR}}$ (b) obtained with MXPOL at 18:55 UTC and $Z_{\mathrm{DR}}$ (c) at 21:05 UTC on 12 February 2008. Colour scales are indicated.

The subsequent cells moved along the zipping of the two boundaries. These boundary layer features normally trigger deep convection (Carbone et al., 1997). In this case, the convective cell was predicted more than 30 min before its mature phase. 



Fig. 8. $2^{\circ}$ PPI of reflectivity $(Z-$ dBZ) at 18:35 UTC (a), 19:20 UTC (b) and 1951 (c) obtained with MXPOL on 20 March 2008. Colour scale is indicated.

In several instances, the incoming see breeze interact with the urban heat island by MASP (Fig. 3a) and produces very deep convection with heavy rainfall, gust winds, lightning and hail that cause occasional deaths, damage to property and disruption of economics.

Figure 7 shows $2^{\circ}$ PPI of the differential reflectivity $Z_{\mathrm{DR}}$ and reflectivity $Z$ at $18: 55 \mathrm{UTC}$ (15:55 LT) on 12 February 2008. It shows a well defined sea breeze front moving towards MXPOL from SE. The reflectivity field in Fig. 7b shows ground echoes reflectivities between -10 to $65 \mathrm{dBZ}$ at $45-\mathrm{km}$ range, three convective cells $(-10<Z<50 \mathrm{dBZ})$ in the far east and the sea breeze front $(-10<Z<15 \mathrm{dBZ})$. It triggered severe thunderstorms about $30 \mathrm{~min}$ after moving over the MASP (not shown). The differential reflectivity $Z_{\mathrm{DR}}$ field (Fig. 7a) shows that the forward part of the sea breeze front is dominated by negative values and, the backward part, by positive values. It suggests that hydrometeors (e.g. insects and shaft) at the forward site of the sea breeze front tend to be oriented vertically as they are lifted and moved backward. Noteworthy, the sea breeze front can not be seen even at very close range.
The more intense ground echoes (Fig. 7b) tend to be associated with very low negative $Z_{\mathrm{DR}}$. Furthermore, the insects (e.g. mosquitoes) carried along by moving boundaries are small and to a first approximation are within the Rayleigh backscattering region. But if not, $Z_{\mathrm{DR}}$ should be either high negative or positive. Figure 7 shows low positive and negative $Z_{\mathrm{DR}}$ values as well as the reflectivity associated to the sea breeze front.

A final instance of the sea breeze front and its effect on convection over MASP is shown in Fig. 8. It shows $2^{\circ}$ PPI of unfiltered reflectivity $Z$ fields at 18:35, 19:20 and 19:51 UTC on 20 March 2008. Unfiltered reflectivity is without filtering ground clutter. Other filters are applied to reduce noise to improve measurements. Figure 8 a shows ground echoes, convective cells at 60 and $180^{\circ}$ azimuth and the sea breeze front $(-5<Z<25 \mathrm{dBZ})$ almost perpendicular to the $150^{\circ}$ azimuth close to the $20-\mathrm{km}$ range. It reached the $10-\mathrm{km}$ (Fig. 8b) and 5-km (Fig. 8c) ranges at 19:20 and 19:51 UTC, respectively.

Figure 8c shows intense convective cells parallel to the region where the sea breeze front was moving 75 min earlier. 
Thus, the detection of the sea breeze front increases the nowcasting lead time in more than $30 \mathrm{~min}$ before any significant precipitation is observed. The increase in leading time in relationship to the conventional S-band radar is crucial for nowcasting flood related events which correspond to $65 \%$ of all flood events during spring and summer.

\section{MXPOL microphysical characterization of heavy rainfall}

The dynamics and microphysics of a squall line measured by MXPOL starting at 19:50 UTC on 26 April 2007 is qualitatively analysed. The measurements of the most intense region of the squall line are shown in Fig. 9 through a sequence of $2^{\circ}$ PPIs of reflectivity $Z_{\mathrm{H}}(\mathrm{a})$; radial velocity $V_{\mathrm{R}}(\mathrm{b})$; spectral width $W$ (c); differential reflectivity $Z_{\mathrm{DR}}$ (d); differential propagation phase $\varphi_{\mathrm{DP}}$ (e); specific differential phase $K_{\mathrm{DP}}(\mathrm{f})$; and correlation coefficient $\rho_{\mathrm{oHV}}(\mathrm{g})$. The area of high reflectivities near the centre of Fig. 9a is associated to radial velocities $V_{\mathrm{R}} \sim 25 \mathrm{~m} \mathrm{~s}^{-1}$ (Fig. 9b) and turbulence $W \sim 3 \mathrm{~m} \mathrm{~s}^{-1}$ (Fig. 9c), large drops $Z \sim 3 \mathrm{~dB}$ (Fig. 9d), lower $\varphi_{\mathrm{DP}}<100^{\circ}$ (Fig. 9f) and $K_{\mathrm{DP}}<3^{\circ} \mathrm{km}^{-1}$. Figure 9 shows constant elevation fields of the polarimetric variables. At the leading edge of the squall line, the radar beam is higher in the atmosphere where winds are stronger given that increase of the wind in this highly baroclinic environment. So, closer to the radar, the wind is closer to the ground but and in a region of stratiform region. Here, polarimetric variables intensities are indicated magnitudes. They are not meant to establish any correlations among variables at all.

The correlation coefficient $\rho_{\mathrm{oHV}}$ within the precipitating region is between 0.95 and 0.99 and indicates again the good quality of the polarimetric measurements. The correlation coefficient is a good indicator of the radar hardware quality for weather echoes, especially under significant rainfall rates. It tends to be lower at the edge of the thunderstorms where small drops evaporate due to entrainment of drier environment air.

The low elevation PPIs of Fig. 9 are passing through the warm layer of the thunderstorms dominated by drops of various sizes as $Z_{\mathrm{DR}}$ (Fig. 9d) and $K_{\mathrm{DP}}$ (Fig. 9f) fields are positive except where attenuation is more significant as depicted by the circumference in Fig. 9f. It is caused by large rain drops and hail aloft at the leading edge of the squall line. On another research work, to be published elsewhere, attenuation and $Z_{\mathrm{DR}}$ bias (Fig. 5d) are corrected by the selfconsistent method (Vivekanandan et al., 2003).

Figure 10 shows cross-sections through the squall line where attenuation is more significant. The direction of the cross-section is indicated in Fig. 9a by the line AA. The $Z_{\mathrm{h}}$ cross-section in Fig. 10a shows a slanted core of reflectivities above $45 \mathrm{dBZ}$ from the surface at $30 \mathrm{~km}$ range to $8 \mathrm{~km}$ altitude and $35 \mathrm{~km}$ range. The circumference indicates where $Z_{\mathrm{h}}$ attenuation is the greatest. One might notice that collocated
$K_{\text {DP }}$ measurements are not as much affected by large drops (Fig. 10f). The elevated core of high reflectivity at the leading edge is where the strongest updrafts (Fig. 10b). Anvils precede the heaviest rainfall at surface in about $20 \mathrm{~km}$ where radial divergence is highest at $9 \mathrm{~km}$ altitude (Fig. 10b). Figure $10 \mathrm{~h}$ shows a photo of the anvil 40 min early as the squall line moved over MXPOL site. The analysis above is based on a conceptual model of deep and fast moving squall line and the underlying dynamics of radial velocities patterns, but one also notices the location of the overshooting top (Fig. 10a). Additionally, the author was there making the measurements and observing the approaching squall line through its mature and decaying phases with real-time displays to analyse these features. So, radial divergence aloft and radial vorticity patterns are close to the main updraft. No wind retrieval methods were used since the goal is to look at the original data, understand it in the light of a well-known phenomenon.

Radial velocities are in general positive. At the rear side of the squall line near the surface $V$ is between 10 to $15 \mathrm{~m} \mathrm{~s}^{-1}$. The maximum radial velocities are in the anvil region $\left(\sim 25 \mathrm{~m} \mathrm{~s}^{-1}\right)$. Radial convergence is highest at $2 \mathrm{~km}$ altitude and at $35 \mathrm{~km}$ range. Another one is observed at $5 \mathrm{~km}$ altitude and at $28 \mathrm{~km}$ range, a region of strong convergence associate to the mid-level rear flow jet. Radial divergence signatures are apparent near the overshooting dome and at the base of the anvil. The spectral width in Fig. 10c shows that the turbulence is higher near the main updraft and at the anvil and lower at the rear of the squall line. It is about 2 to $3 \mathrm{~m} \mathrm{~s}^{-1}$ within and less than $1 \mathrm{~m} \mathrm{~s}^{-1}$ in the rear flank of the squall line; it is higher right below the overshooting top.

The differential reflectivity (Fig. 10d) is above $3.5 \mathrm{~dB}$ near region of highest reflectivity at the surface at $35 \mathrm{~km}$ range. A core of high negative value $(<-3.5 \mathrm{~dB})$ is at the leading edge of the squall line from 2 to $5 \mathrm{~km}$ altitude and 33 to $40 \mathrm{~km}$ range. These negative values are probably to the heavy rainfall attenuation (observed) as large drops are more oval and so attenuate the horizontal reflectivity more significantly. At the same local, $K_{\mathrm{DP}}$ is also larger, consistent with this negative $Z_{\mathrm{DR}}$ region.

Apparently, drops quickly increase in mass at the leading edge of the storm as they move upwards on a strong updraft where the relative horizontal vorticity is negative (Fig. 10c) centred 15 at $2 \mathrm{~km}$ altitude and $33 \mathrm{~km}$ range. $Z_{\mathrm{DR}}$ is close to zero at $31 \mathrm{~km}$ range and $3 \mathrm{~km}$ altitude which suggests the presence of hail (circumference in Fig. 10d). $Z_{\mathrm{DR}}$ is zero for hail and for small drops since both yield similar horizontal and vertical backscattering. $Z_{\mathrm{DR}}$ is positive for large drops. Vertically oriented ice particles yield negative values of $Z_{\mathrm{DR}}$.

The differential propagation phase, the specific differential phase and correlation HV are shown in Fig. 10e-g, respectively. At the leading edge of the squall line $Z_{\mathrm{DR}}$ is negative, $\varphi_{\mathrm{DP}}$ and $K_{\mathrm{DP}}$ are highly positive while $Z_{\mathrm{H}}$ and $\rho_{\mathrm{OHV}}$ are fairly low and turbulence is relatively high. These inconsistent features are due to severe attenuation which limits rainfall quantification based on reflectivity. In this instance, $K_{\mathrm{DP}}$ 

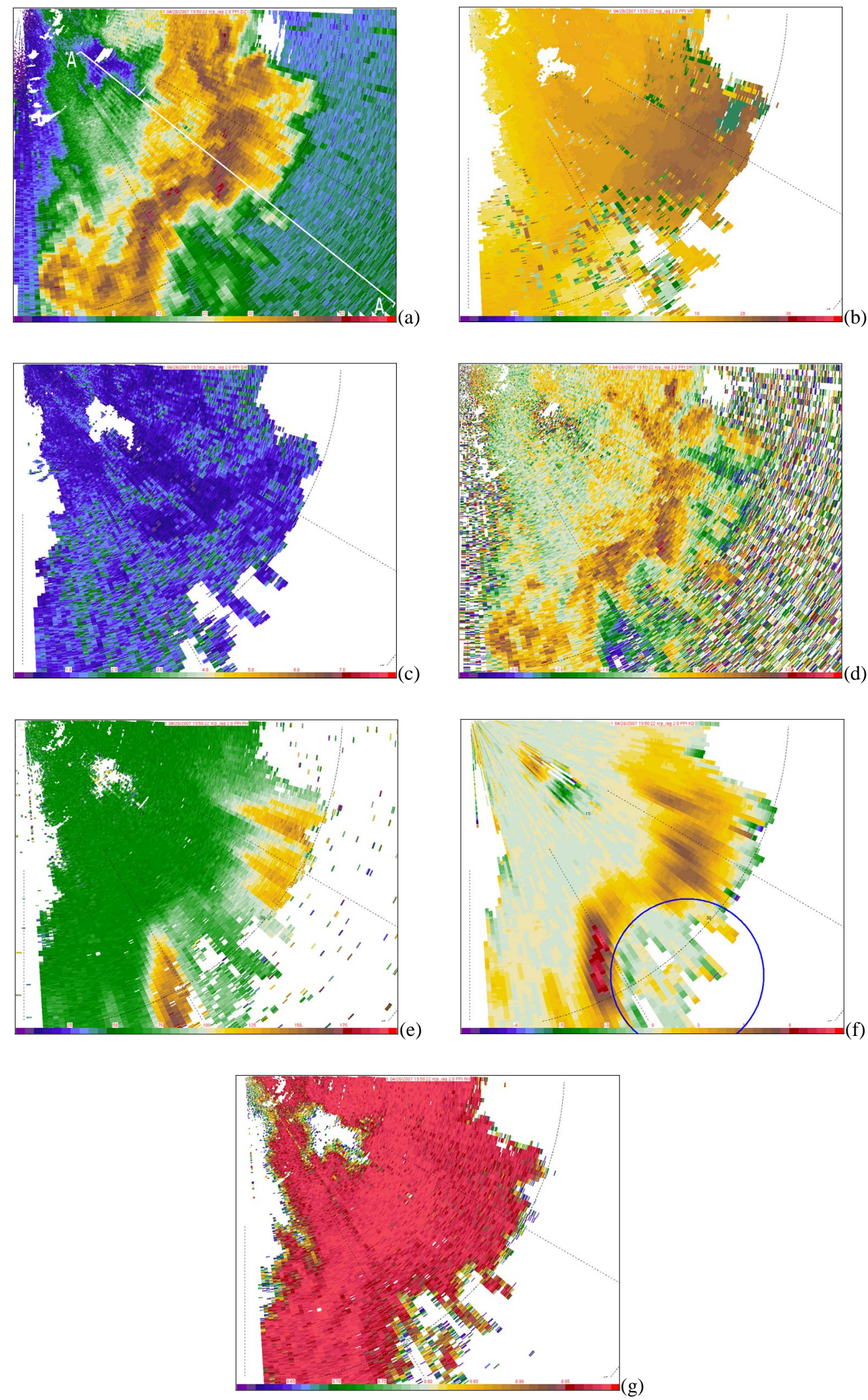

Fig. 9. $2^{\circ}$ PPI of reflectivity $-Z_{\mathrm{h}}(\mathbf{a}) \mathrm{dBZ}$, radial velocity $-V_{\mathrm{r}}(\mathbf{b}) \mathrm{m} \mathrm{s}^{-1}$, spectral width $-\mathrm{SW}$ (c) $\mathrm{m} \mathrm{s}^{-1}$, differential reflectivity $-Z_{\mathrm{DR}}(\mathbf{d})$, differential propagation phase $-\varphi_{\mathrm{DP}}(\mathbf{e})$ degree, specific differential phase $-K_{\mathrm{DP}}(\mathbf{f})$ degree $\mathrm{km}^{-1}$ and correlation coefficient $\mathrm{VH}-\rho_{\mathrm{OHV}}(\mathbf{g})$ obtained with MXPOL at 19:50 UTC on 26 April 2007. Colour scales are indicated. 



(b)


Fig. 10. NW-SE cross-sections of reflectivity $-Z$ (a) dBZ, radial velocity $-V$ (b) $\mathrm{m} \mathrm{s}^{-1}$, spectral width $-\mathrm{SW}$ (c) $\mathrm{ms}^{-1}$, differential reflectivity $-Z_{\mathrm{DR}}(\mathbf{d})$, differential propagation phase $-\varphi_{\mathrm{DP}}(\mathbf{e})$ degree, specific differential phase $-K_{\mathrm{DP}}(\mathbf{f})$ degree $\mathrm{km}^{-1}$ and correlation coefficient VH $-\rho_{\mathrm{oHV}}$ (g) obtained with MXPOL at 19:54 UTC on 26 April 2007. Colour scales are indicated in each cross-section. The photo of the anvil of the squall line $(h)$ was taken looking Northward from MXPOL site at 19:16 UTC on 26 April 2007. 
is less affected by large drops and might result in better rainfall rate estimation.

On the other end at the rear side of the squall line, $Z_{\mathrm{DR}}$ is negative, $\varphi_{\mathrm{DP}}$ is positive and $K_{\mathrm{DP}}$ negative or close to zero and $Z_{\mathrm{H}} \rho_{\mathrm{oHV}}$ are low and turbulence is lower. These features suggest a mixture of hydrometeors with different shapes coexist within the region of significantly negative $Z_{\mathrm{DR}}$, most probably graupel and ice crystals are being brought down by turbulent eddies and mixed with small droplets at the rear of the thunderstorm. These results are consistent with previous studies by Aydin et al. (1995). Since $K_{\mathrm{DP}}$ is less affected by large drops, it might yield better rainfall rate estimation.

Pockets of negative $K_{\mathrm{DP}}$ between 6 and $10 \mathrm{~km}$ altitude at 10,25 and $38 \mathrm{~km}$ range altitude indicate the presence of ice crystals oriented vertically perhaps by the cloud electric field. Lighting strikes (not shown) were more recurrent near the leading edge of the thunderstorms. That might be useful for nowcasting light strikes in thunderstorms electrically charged.

\section{Summary}

MXPOL was designed and built for heavy duty use. The system was tested on various weather and landscape conditions (e.g. thunderstorms overhead, dirty roads and steep terrain). The power generator fuel autonomy allows its use on remote areas. Furthermore, its communication system based on cell phone technology, though limited can be quite useful to transfer products to remote distances.

MXPOL is an important technical and scientific advancement for radar meteorology in Brazil. It is the first of its kind to provide near real-time polarimetric data and products for operational use to monitor and to nowcasting severe weather events in MASP.

Given its greater sensitivity and dynamic range, MXPOL detects the early development of convection and moving boundaries. The mobility and autonomous operating features of MXPOL makes it an important tool for experiments where infrastructure is limited.

The examples of MXPOL polarimetric measurements presented in this work reveal characteristics of tropical weather systems with high spatial and temporal resolution. Doppler radars measure radial velocities, but most dynamic features can be deduced from known patterns. MXPOL detected boundary layer circulation and shallow convection up to 60 $\mathrm{km}$ in range, convergence, divergence, vorticity and turbulence within cloud systems and advection signatures (not shown), cold and warm microphysics, the melting layer and the precursor to lightning since electrical charges are produced within the cold region of a thunderstorm. Ice particles tend to be oriented with the electric field and that can produce negative values of $Z_{\mathrm{DR}}$, especially at the upper part of the thunderstorm, given the vertical alignment of irregular ice particles. So, $Z_{\mathrm{DR}}$ might be used as an indicator of potential lightning strikes (Caylor and Chandrasekar, 1996).

Limited comparisons suggest MXPOL reflectivity measurements are consistent with SPWR measurements though in some instance severely attenuated by heavy rainfall and hail. The auxiliary in situ measurements from a lightning network, rain gages and soundings are being used for microphysical retrievals (Vivekanandan et al., 1998; Gorgucci et al., 2008; Spek at al., 2008) with MXPOL measurements.

MXPOL is the first Brazilian X-POL weather radar to be used operationally to deliver real-time high spatial resolution polarimetric data for hydrometeorological applications. MXPOL is important for several research studies of cloud microphysics, electricity and dynamics, rainfall quantification and verification, 3-D retrievals, intercomparison studies, field experiments, mesoscale and synoptic studies, modelling, data assimilation and integration among other research topics of interest. The next steps include implementing the attenuation correction procedure for MXPOL measurements. MXPOL is also an excellent observational tool for undergraduate and graduate courses as well as training programmes. Lastly, MXPOL is also being used on survey studies to implement new radar sites in Brazil.

Acknowledgements. The author is thankful to The Department of Water and Electrical Energy for providing SPWR data and to many Colleagues at the Institute of Astronomy, Geophysics and Atmospheric Sciences and at Barueri Civil Defense Group who significantly contributed to the success of the MXPOL project and operations, respectively. This research and MXPOL were sponsored by The State of São Paulo Research Support Foundation (FAPESP) under granted 13952-2 and by National Research Council - CNPq under grant 304978/2011-6. The author is also very grateful to two anonymous reviewers that greatly improved this manuscript.

Edited by: M. Zribi

\section{References}

Aydin, K., Bringi, V. N., andLiu, L.: Rain-rate estimation in the presence of hail using S-band specific differential phase and other radar parameters, J. Appl. Meteorol., 34, 404-410, 1995.

Anagnostou, E. N., Anagnostou, M. N., Krajewski, W. F., Kruger, A., and Miriovsky, B. J.: High-resolution rainfall estimation from X-band polarimetric radar measurements, J. Hydrometeorol., 5, 110-128, 2004.

Anagnostou, M. N., Anagnostou, E. N., and Vivekanandan, J.: Correction for rain path specific and differential attenuation of $\mathrm{X}$ band dual-polarization observations, IEEE T. Geosci. Remote, 44, 2470-2480, 2006.

Berne, A. and Uijlenhoet, R.: Quantitative analysis of X-band weather radar attenuation correction accuracy, Nat. Hazards Earth Syst. Sci., 6, 419-425, doi:10.5194/nhess-6-419-2006, 2006. 
Carbone, R. E., Keenan, T. D., Wilson, J. W., and Hacker, M.: Bounday layer structures and the role of breezes in forcing deep island convection, 28th Conference on Radar Meteorology, Paper 14A2, Austin, Texas, USA, 1997.

Caylor, I. J. and Chandrasekar, V.: Time-varying ice crystal orientation in thunderstorms ob- served with multiparameter radar, IEEE T. Geosci. Remote, 34, 847-858, 1996.

Fereira, M. J., Oliveira, A. P., and Soares, J.: Anthropogenic heat in the City of São Paulo, Brazil, Theor. Appl. Climatol., 104, 4356, doi:10.1007/s00704-010-0322-7, 2011.

Georgis, J. F., Pujol, O., and Sauvageot, H.: A dual wavelength polarimetric method to identify cloud component in warm precipitating systems, 4th European Conference on Radar in Meteorology and Hydrology, Barcelona, Spain, 276-278, 2006.

Gorgucci, E. and Chandrasekar, V.: Evaluation of attenuation correction methodology for dual-polarization radars: application to X-band systems, J. Atmos. Ocean. Tech., 22, 1195-1206, 2005.

Gorgucci, E., Chandrasekar, V., and Baldini, L.: Microphysical retrievals from dual-polarization radar measurements at X band, J. Atmos. Ocean. Tech., 25, 1668-1681, 2008.

$\mathrm{Hu}$, M., Xue, M., Gao, J., and Brewster, K.: 3DVAR and cloud analysis with WSR-88D level-II data for the prediction of the Fort Worth, Texas, Tornadic Thunderstorms, Part I: Cloud analysis and its impact, Mon. Weather Rev., 134, 675-798, 2006 a.

Hu, M., Xue, M., Gao, J., and Brewster, K.: 3DVAR and cloud analysis with WSR-88D level-II data for the prediction of the Fort Worth, Texas, Tornadic Thunderstorms, Part II: Impact of radial velocity analysis via 3DVAR, Mon. Weather Rev., 134, 699-721, $2006 \mathrm{~b}$

Matrosov, S. Y., Clark, K. A., Martner, B. E., and Tokay, A.: X-band polarimetric radar measure- ments of rainfall, J. Appl. Meteorol., 41, 941-952, 2002.

Melnikov, A. V., Melnikov, V. M., and Ryzhkov, A. V.: On the differential phase in the melting layer 32nd Conference on Radar Meteorology, Paper P9R.9, Tucson, Arizona, USA, 2005.

Park, S.-G., Maki, M., Iwanami, K., Bringi, V. N., and Chandrasekar, V.: Correction of radar reflectivity and differential reflectivity for rain attenuation at X-band, Part I: Theoretical and empirical basis, J. Atmos. Ocean. Tech., 22, 1621-1632, 2005.
Pereira Filho, A. J., Massambani, O., Hallak, R., and Karam, H.: A hydrometeorological forecast system for the Metropolitan Area of São Paulo, WWRP Workshop on Nowcasting and Very Forecasting, CDROM Proceedings, Toulouse, France, 2005.

Pereira Filho, A. J., Santos, P. M., Camargo, R., Festa, M., Funari, F. L., Salum, S. T., Oliveira, C. T., Santos, E. M., Lourenço, P. R., da Silva, E. G. W. G., and Fialho, M. A.: Anthropic impacts on the climate of the Metropolitan Area of São Paulo, Bull. Brazilian Meteorol. Soc., 30, 48-56, 2007.

Pujol, O., Georgis, J. F., Féral, L., and Sauvageot, H.: Degradation of radar reflectivity by cloud attenuation at microwave frequency, J. Atmos. Ocean. Tech., 24, 640-657, 2007.

Spek, A. L. J., Unal, C. M. H., Moisseev, D. N., Russchenberg, H. W. J., Chandrasekar, V., and Dufournet, Y.: A New Technique to Categorize and Retrieve the Microphysical Properties of Ice Particles Above the Melting Layer Using Radar Dual-Polarization Spectral Analysis, J. Atmos. Ocean. Tech., 25, 482-497, 2008.

Vivekanandan, J., Zrnic, D. S., Ellis, S. M., Oye, D., Ryzhkov, A. V., and Straka, J.: Cloud microphysics retrieval using S-band dual-polarization radar measurements, B. Am. Meteorol. Soc., 80, 381-388, 1998.

Vivekanandan, J., Zhang, G., Ellis, S. M., Avery, S., and Rajopadyahya, D.: Radar reflectivity calibration using differential propagation phase measurement, Radio Sci., 38, 1-14, 2003.

Weisman, M. L., Skamarock, W. C., and Klemp, J. B.: The resolution dependence of explicitly modelled convective systems, Mon. Weather Rev., 125, 504-520, 1997.

Xue, M. and Martin, W. J.: A high-resolution modelling study of the 24 May 2002 dryline case during IHOP, Part II: Horizontal Convective Rolls and Convective Initiation, Mon. Weather Rev., 134, 172-191, 2006.

Xue, M., Wang, D.-H., Gao, J., Brewster, K., and Droegemeier, K. K.: The Advanced Regional Prediction System (ARPS), stormscale numerical weather prediction and aata assimilation, Meteorol. Atmos. Phys., 82, 139-170, 2003.

Zrnic, D. S., Melnikov, V. M., and Carter, J. K.: Calibrating differential reflectivity on the WSR-88D, J. Atmos. Ocean. Tech., 23, 944-951, 2006. 